\title{
Global Epidemiology of Tuberculosis
}

\author{
Philippe Glaziou, MD, MPhil ${ }^{1}$ Dennis Falzon, MD, MSc ${ }^{1}$ Katherine Floyd, MA, MSc, $\mathrm{PhD}^{1}$ \\ Mario Raviglione, $\mathrm{MD}^{1}$
}

1 Stop TB Department (STB), HIV/AIDS, TB, Malaria and Neglected
Tropical Diseases Cluster (HTM), World Health Organization, Geneva,
Switzerland

Address for correspondence Philippe Glaziou, MD, Stop TB

Department (STB), HIV/AIDS, TB, Malaria and Neglected Tropical

Diseases Cluster (HTM), World Health Organization, 20, Avenue Appia,

Semin Respir Crit Care Med 2013;34:3-16.

CH-1211 Geneva 27, Switzerland (e-mail: glazioup@who.int).

\begin{abstract}
With 1.4 million deaths in 2011 and 8.7 million new cases, tuberculosis (TB) disease remains a global scourge. Global targets for reductions in the epidemiological burden of TB have been set for 2015 and 2050 within the context of the Millennium Development

\section{Keywords}

- tuberculosis

- epidemiology

- burden

- incidence

- prevalence

- mortality Goals (MDGs) and by the Stop TB Partnership. Achieving these targets is the focus of national and international efforts in TB control, and demonstrating whether or not they are achieved is of major importance to guide future and sustainable investments. This paper discusses the methods used to estimate the global burden of TB; estimates of incidence, prevalence, and mortality for 2011 , combined with assessment of progress toward the 2015 targets for reductions in these indicators based on trends since 1990 and projections up to 2015; trends in TB notifications and in the implementation of the Stop TB Strategy; and prospects for elimination of TB by 2050.
\end{abstract}

With 1.4 million deaths resulting from tuberculosis (TB) in $2011^{1}$ the disease competes with the human immunodeficiency virus (HIV) as the top cause of death from an infectious agent. ${ }^{2}$ TB still takes a huge toll, especially among the poorest. It is a leading killer among people in the most economically productive age groups and those living with HIV. ${ }^{3}$ Those who are cured of TB can be left with lifetime sequelae that substantially reduce their quality of life. ${ }^{4}$ Following neglect of the disease during the $1980 \mathrm{~s},{ }^{5,6}$ the recognition of its substantial burden has kept TB control high on the international public health agenda since the early 1990s. The dramatic effect of the HIV epidemic on numbers of TB cases and deaths in Africa, evidence that short-course chemotherapy is among the most cost-effective of all healthcare interventions, ${ }^{7,8}$ and most recently the global concerns about the emergence of multidrug-resistant and extensively drug resistant TB (MDR and XDR-TB) have emphasized the need to address TB more effectively on a global scale.

Global targets for reductions in the epidemiological burden of TB have been set for 2015 and 2050 within the context of the Millennium Development Goals (MDGs) and separately by the Stop TB Partnership, a global coalition of stakeholders established to coordinate international efforts ( - Table 1 ). The principal MDG target is that the incidence rate should be falling by 2015. The additional targets set by the Stop TB
Partnership are that prevalence and death rates should be halved by 2015 compared with their level in 1990, and that TB should be eliminated as a public health problem by 2050 , defined as less than one case per million population. Reaching these targets is the focus of national and international efforts in TB control, and the World Health Organization (WHO) has established a Global Task Force on TB Impact Measurement ${ }^{9}$ to ensure the best possible evaluation of whether or not they are achieved. To reach these goals WHO recommends the Stop TB strategy ${ }^{10}$ ( - Table 2). The strategy comprises best practices in the diagnosis and treatment of patients with active TB, approaches to address major epidemiological and system challenges of today, and the promotion of research for innovations. It was launched in 2006 and underpins the Global Plan 2011-2015, ${ }^{10}$ a comprehensive and budgeted plan to reach the global targets. ${ }^{11-13}$

Each year, WHO publishes estimates of TB incidence, prevalence, and mortality at global, regional, and national levels, along with an analysis of progress toward achievement of global targets. ${ }^{1}$ This paper covers the methods used to estimate the global burden of TB; trends in incidence, prevalence, and mortality from 1990 to 2011, with projections up to 2015; progress in the global response to $\mathrm{TB}$, with special attention given to MDR-TB and TB/HIV, and prospects for elimination of TB by 2050.
Issue Theme Mycobacterial Infections; Guest Editor, Charles L. Daley, MD.
Published by Thieme Medical Publishers, Inc., 333 Seventh Avenue, New York, NY 10001, USA. Tel: +1(212) 584-4662.
DOI http://dx.doi.org/ 10.1055/s-0032-1333467. ISSN 1069-3424. 
4 Global Epidemiology of Tuberculosis Glaziou et al.

Table 1 Goals, target, and indicators for tuberculosis control

\begin{tabular}{|c|}
\hline Health in the Millennium Development Goals \\
\hline Goal 6: Combat HIV/AIDS, malaria and other diseases \\
\hline Target 6c: Halt and begin to reverse the incidence of malaria and other major diseases \\
\hline Indicator 6.9: Incidence, prevalence, and death rates associated with TB \\
\hline Indicator 6.10: Proportion of TB cases detected and cured under DOTS \\
\hline Stop TB Partnership targets \\
\hline $\begin{array}{l}\text { By 2005: At least } 70 \% \text { of people with sputum smear-positive TB will be diagnosed (i.e., under the DOTS strategy), } \\
\text { and at least } 85 \% \text { successfully treated. The targets of a case detection rate of at least } 70 \% \text { and a treatment success rate } \\
\text { of at least } 85 \% \text { were first set by the World Health Assembly of the World Health Organization in } 1991 .\end{array}$ \\
\hline By 2015: The global burden of TB (per capita prevalence and death rates) will be reduced by 50\% relative to 1990 levels. \\
\hline By 2050: The global incidence of active TB will be less than one case per million population per year. \\
\hline
\end{tabular}

Abbreviation: DOTS, directly observed treatment, short course.

\section{Methods}

The burden of disease caused by TB can be measured in terms of incidence, defined as the number of new plus relapse (or recurrent) cases of TB arising in a given time period, usually 1 year; prevalence, defined as the number of cases of TB at a given point in time; and mortality, defined as the number of deaths caused by TB in a given time period, usually 1 year.

Measuring the incidence of TB at the national level has never been done because it would require active follow-up over 1 or 2 years of nationally representative cohorts of tens of thousands of people at high cost and with extremely challenging logistics. Surveys of infection using tuberculin skin testing have been used in the past to derive estimates of incidence of TB disease, but the interpretation of such surveys is typically very difficult, especially where a high prevalence of HIV infection has altered the natural course of the disease. ${ }^{9}$ The best alternative is to estimate incidence from routine surveillance systems, in which case reports are more or less complete, such that notifications can be considered a close proxy of incidence. This is possible in countries such as the United Kingdom and the United States, where there is a long tradition of reporting TB morbidity and mortality and where operational research has been used to quantify the small fraction of cases that are treated but not reported to surveillance systems. ${ }^{14}$ Surveillance systems in many countries are not yet comprehensive enough to provide a direct measure of TB incidence. Many cases are either treated but not reported (e.g., when cases are treated in the private sector or in general hospitals that are not part of services linked to national programs) or go undiagnosed (e.g., when people with no health insurance and no social protection lack access to health care or when the laboratory network is underperforming). In these countries, estimating incidence in absolute terms and trends over time requires an evaluation of the quality and coverage of available TB notification data. Evaluation of data quality includes analysis of the completeness of reporting, whether there are duplicate or misclassified records, ${ }^{15}$ and the internal and external consistency of national and subnational data (internal consistency means data are consistent over time and space, or that variation can be explained; external consistency means that data are consistent with existing evidence about the epidemiology of TB). ${ }^{16}$ Evaluation of the coverage of TB notification data involves analysis of the extent to which trends in notifications or trends in reported TB deaths from vital registration systems reflect trends in incidence rates or the extent to which they reflect changes in other factors (such as programmatic efforts to find and treat more cases). An example from Kenya illustrates how the effect of the HIV epidemic and case-finding efforts on trends in TB notifications can be separated and used to improve estimates of trends in TB incidence rates. ${ }^{17}$ Even when notification data from all reporting units are available and of high quality and when they appear to be a reasonably good proxy of trends in TB incidence, the reported data are not necessarily sufficient to estimate TB incidence in absolute terms. To do this, an analysis of the fraction of TB cases that are being captured in official notification systems is required. ${ }^{14}$ The major reasons why cases are missed from official notification data include laboratory errors, ${ }^{18}$ lack of notification of cases by public ${ }^{19}$ and private providers, ${ }^{20}$ failure of people accessing health services to be identified as potential TB cases, ${ }^{21}$ and lack of access to health services. ${ }^{22}$ Operational research (such as capture-recapture studies) as well as supporting evidence (such as whether prescriptions for TB drugs are available in the private sector, and the knowledge, attitudes, and practices of staff managing people suspected of having TB in primary health care facilities) can be used to assess the fraction of cases that are missing from official notification data. ${ }^{14,23-26}$ WHO is working closely with countries to review and update estimates of TB incidence on a regular basis.

In countries with a high burden of $\mathrm{TB}$, prevalence can be directly measured in nationwide surveys using sample sizes of around 50,000 people; costs range from 1 to 4 million US\$ per survey. ${ }^{27,28}$ In recent years, several countries have successfully measured the prevalence of TB disease through such surveys, ${ }^{29-32}$ despite logistic challenges and high operational costs. Because prevalence typically falls more quickly than TB incidence in response to control efforts, a series of surveys conducted at relatively wide intervals of 7 to 10 years can be very useful for capturing large changes in the epidemiological burden of TB in high-burden countries. For instance, 
Table 2 The Stop TB strategy 97,98

Vision, goal, objectives, and targets

Vision

A world free of tuberculosis (TB)

Goal

To dramatically reduce the global burden of TB by 2015 in line with the Millennium Development Goals and the Stop TB Partnership targets

Objectives

- Achieve universal access to high-quality diagnosis and patient-centered treatment

- Reduce the human suffering and socioeconomic burden associated with TB

- Protect poor and vulnerable populations from TB, TB/HIV, and multidrug-resistant TB

- Support development of new tools and enable their timely and effective use

Targets

- MDG 6, Target 8: ...halted by 2015 and begun to reverse the incidence...

- Targets linked to the MDGs and endorsed by the Stop TB Partnership:

- By 2005: detect at least $70 \%$ of new sputum smear-positive TB cases and cure at least $85 \%$ of these cases

- By 2015: reduce prevalence of and death due to TB by 50\% relative to 1990

- By 2050: eliminate TB as a public health problem ( $<1$ case per million population)

\section{Components of the Stop TB strategy}

\section{Pursue high-quality DOTS expansion and enhancement}

- Secure political commitment, with adequate and sustained financing

- Ensure early case detection, and diagnosis through quality-assured bacteriology

- Provide standardized treatment with supervision and patient support

- Ensure effective drug supply and management

- Monitor and evaluate performance and impact

2. Address TB-HIV, MDR-TB, and the needs of poor and vulnerable populations

- Scale-up collaborative TB/HIV activities

- Scale-up prevention and management of multidrug-resistant TB (MDR-TB)

- Address the needs of TB contacts and of poor and vulnerable populations

3. Contribute to health system strengthening based on primary health care

- Help improve health policies, human resource development, financing, supplies, service delivery and information

- Strengthen infection control in health services, other congregate settings and households

- Upgrade laboratory networks, and implement the Practical Approach to Lung Health (PAL)

- Adapt successful approaches from other fields and sectors, and foster action on the social determinants of health

4. Engage all care providers

- Involve all public, voluntary, corporate and private providers through Public-Private Mix (PPM) approaches

- Promote use of the International Standards for Tuberculosis Care (ISTC)

5. Empower people with TB, and communities through partnership

- Pursue advocacy, communication and social mobilization

- Foster community participation in TB care

- Promote use of the Patients' Charter for Tuberculosis Care

6. Enable and promote research

- Conduct program-based operational research and introduce new tools into practice

- Advocate for and participate in research to develop new diagnostics, drugs and vaccines

Source: http://www.who.int/tb/strategy/en/. 


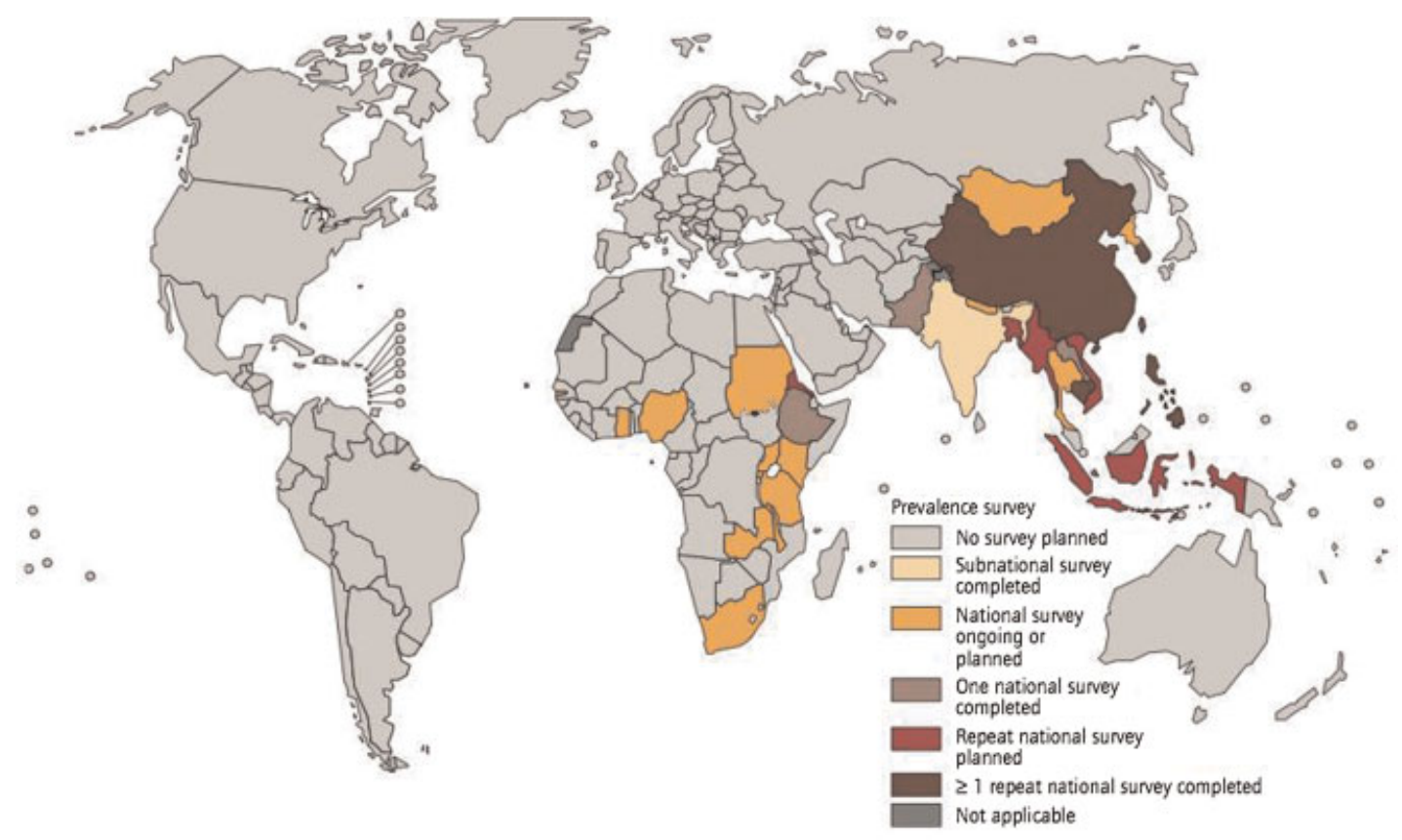

Fig. 1 Countries in which surveys of the prevalence of tuberculosis have been implemented since 1990 or are planned in the near future.

Cambodia and China have conducted repeat prevalence surveys showing significant declines in prevalence over time.

In total, 13 high-burden countries conducted at least one national prevalence survey between 1990 and 2011, and 8 of them have conducted at least one survey according to methods recommended by WHO. ${ }^{27}$ WHO recommends TB prevalence surveys in 22 priority countries to have a sound understanding of the burden of disease caused by $\mathrm{TB}$, to contribute to the assessment of whether the 2015 global targets are reached, and to provide a baseline for measurement of progress post-2015. Prevalence surveys have proved extremely useful for designing and adapting national TB control program strategies. It is anticipated that $\sim 20$ countries ( $\boldsymbol{- F i g . ~ 1 ) ~ w i l l ~ i m p l e m e n t ~ a ~ p r e v a l e n c e ~ s u r v e y ~ b e t w e e n ~}$ 2010 and 2015. As a result, a large proportion of the global burden of TB as expressed in terms of TB prevalence will be directly measured from population-based surveys by 2015 , as opposed to indirectly estimated from statistical modeling. Repeat surveys that allow measurement of trends in disease burden have been implemented in the Republic of Korea, China, Cambodia, and the Philippines over the past 2 decades, and Viet Nam and Myanmar will conduct repeat surveys around 2015.

TB mortality among HIV-negative people can be directly measured if national vital registration (VR) systems of high coverage-in which causes of death are accurately coded according to the latest revision of the International Classification of Diseases (ICD-10)-are in place. ${ }^{33}$ Sample VR systems covering representative areas of the country (as in China) provide a valuable interim solution. By May 2012, 126 countries had reported data to WHO from vital registration systems. ${ }^{1}$ Mortality surveys can also be used to directly measure deaths caused by TB. In 2011, most countries with a high burden of TB still lacked national or sample VR systems (particularly in Africa) and few had conducted mortality surveys (-Fig. 2). TB mortality among people who are HIV-positive is hard to measure, even when VR systems are in place, because deaths in this group are coded as HIV deaths, and contributory causes (such as TB) are generally not reliably recorded. This will need to be corrected to permit a proper assessment of TB mortality. In the interim, cohorts of patients who are HIV-positive that are well monitored in terms of care and autopsy studies provide very useful data on contributory causes of acquired immunodeficiency syndrome (AIDS) deaths.

Estimates of MDR-TB are derived from periodic surveys conducted by countries among a sample of patients with TB presenting for treatment, which is representative of a whole country or part of it. In about 60 countries, results from routine drug-susceptibility testing (DST) used in the course of clinical investigation of patients with TB are also used for surveillance purposes, given that the coverage of patients is sufficiently comprehensive. Standardized methods for conducting drug-resistance surveillance are generally applied in countries. ${ }^{34}$ For countries without representative data, a modeled estimate based on the most recent data from countries in the same region with a comparable epidemiological profile is used as an approximation.

\section{Epidemiology}

TB is contagious and airborne. ${ }^{35}$ It is a disease of poverty that thrives where social and economic determinants of ill health prevail, and it affects mostly young adults in their most productive years; $95 \%$ of TB deaths are in the developing world. ${ }^{1}$ About one third of the world's population is estimated to be latently infected with TB bacteria. ${ }^{36}$ Only a small 


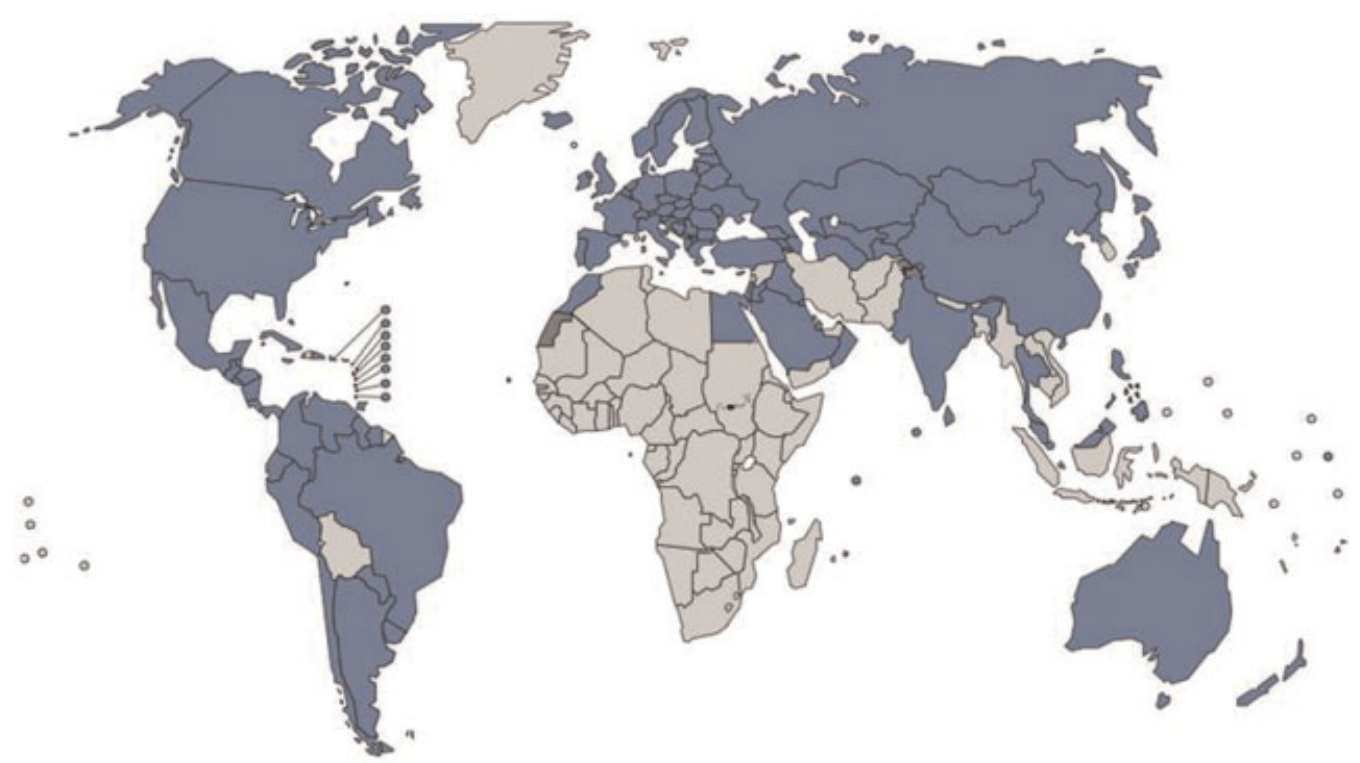

Fig. 2 Countries (in blue) for which tuberculosis mortality is estimated directly using measurements from vital registration systems and/or mortality surveys.

proportion of those infected will become sick with $\mathrm{TB},{ }^{37,38}$ but people with weakened immune systems have a much greater risk of falling ill from TB. In particular, a person living with HIV is over 15 times more likely to develop active TB. ${ }^{1}$ We know from historical data that, left untreated, smearpositive TB has a 10-year case fatality variously reported between 53 and 86\%, with a weighted mean of $70 \%{ }^{39}$ compared with $\sim 3 \%$ of HIV-uninfected treated patients with TB expected to die due to TB. ${ }^{40}$

\section{Incidence}

In 2011, there were an estimated 8.7 million incident cases of TB (range, 8.3 million to 9 million) globally, equivalent to 125 cases per 100,000 population. Most of the estimated cases in
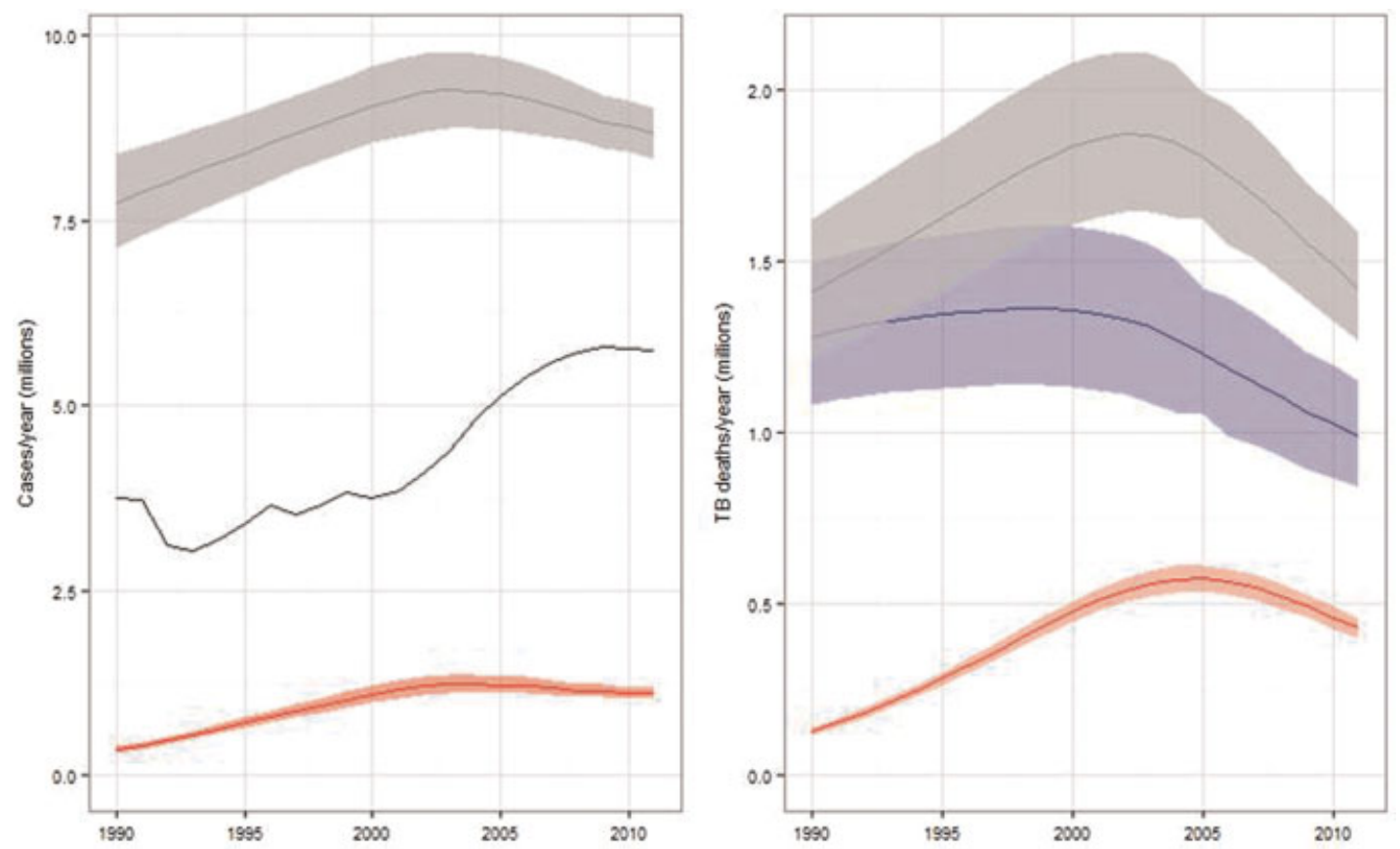

Fig. 3 Global trends in estimated tuberculosis (TB) incidence and estimated TB mortality. Left: global trends in estimated incidence including human immunodeficiency virus (HIV)-negative and HIV-positive TB (gray) and estimated incidence of HIV-positive TB (red). The solid black line shows global trends in case notification rates (all forms of TB). Note: Case notification rates are consistently lower than incidence due to missed cases (detected but not reported or not detected). Right: global trends in estimated TB mortality including TB-associated acquired immunodeficiency syndrome (AIDS) deaths (gray), in HIVnegative cases (blue), in HIV-positive cases (red). Shaded areas represent uncertainty bands. 
2011 occurred in Asia (59\%) and Africa (26\%). The largest estimated numbers of incident cases in 2011 were in India (uncertainty range 2.0 million to 2.5 million) and China ( 0.9 million to 1.1 million). Of the 8.7 million incident cases, an estimated 0.49 million were children ( 0.47 to 0.51 million), and 2.9 million (2.6 to 3.2 million) occurred among women. Of the 8.7 million incident cases in 2011, 1.1 million (1.0 to 1.2 million or 12 to $14 \%$ ) were among people living with HIV. The proportion of TB cases coinfected with HIV was the highest in countries in the African Region; overall, 39\% of TB cases were estimated to be coinfected with HIV in this region, which accounted for $79 \%$ of TB cases among people living with HIV.

Globally, incidence rates increased from 1990 up to around 2001, and then started to fall (-Fig. 3). If recent trends are sustained, MDG Target 6.c will be achieved. The absolute number of incident cases has started to fall very slowly since the early to mid-2000s, when the decline in the incidence rate started to exceed the rate of growth in the world's population. Incidence rates are declining in all of WHO's six regions (-Fig. 4). The current rate of decline varies from less than $1 \%$ per year in the Eastern Mediterranean Region to 3.1\% in Africa and 8.5\% per year in Europe.

\section{Mortality}

A total of $\sim 1.4$ million people (range, 1.3 million to 1.6 million) died of TB in 2011, of whom 0.5 million were women. In 2011 the best estimate of the number of TB deaths worldwide fell below 1 million among people who were HIV-negative, being around 990,000 with an uncertainty interval of 0.84 million to 1.1 million (-Fig. 3 ). There were also an additional 0.43 million HIV-associated deaths (range, 0.40 million to 0.46 million). HIV had the greatest impact on TB mortality in Africa ( - Fig. 4). Globally, mortality rates have fallen by $41 \%$ since 1990 ; the current forecast suggests that the Stop TB Partnership's target of a 50\% reduction by 2015 compared with a baseline of 1990 will be achieved. Mortality rates (excluding HIV) are also declining in all of WHO's regions (-Fig. 5 ).

Patterns of TB mortality show a rise and fall in most eastern European countries ( $\mathbf{- F i g . ~ 6 ) . ~ T h e ~ r e s u r g e n c e ~ o f ~ T B ~}$ in eastern European countries during the 1990s can be explained by the major political, economic, and social disruption associated with the breakup of the Soviet Union in 1991, and related failures in TB control and provision of health care. $^{41}$

Antiretroviral therapy (ART) is expected to play an increasing role in preventing TB deaths as coverage expands ( $\sim 16 \%$ of notified TB cases estimated to be infected with HIV globally were on ART in 2010). ${ }^{42-44}$ ART and isoniazid prophylaxis will also increasingly contribute to prevention of TB in individuals with both HIV infection and latent TB infection.

\section{Prevalence}

There were an estimated 12 million prevalent cases (range, 10 to 13 million) of TB in 2011. The prevalence rate has fallen by $36 \%$ globally since 1990 . However, current forecasts suggest that the Stop TB Partnership's target of halving TB prevalence by 2015 compared with a baseline of 1990 will not be met worldwide. Regionally, prevalence rates are declining in all of WHO's regions. The Region of the Americas halved the 1990 level of TB prevalence by around 2005, well in advance of the target year of 2015, and the Western Pacific Region is close to doing so. Achieving the 50\% reduction target by 2015 appears feasible in the European and Southeast Asia Regions, but not in the African and Eastern Mediterranean Regions.

In the African and European Regions, prevalence rates increased substantially during the 1990s, and by 2007 were still far above the 1990 level in the African Region and just back to the 1990 level in the European Region. With limited access to ART, HIV has probably had a smaller effect on TB prevalence than on incidence because the duration of TB among patients infected with HIV is relatively short: for people with advanced HIV infection, the progression to severe

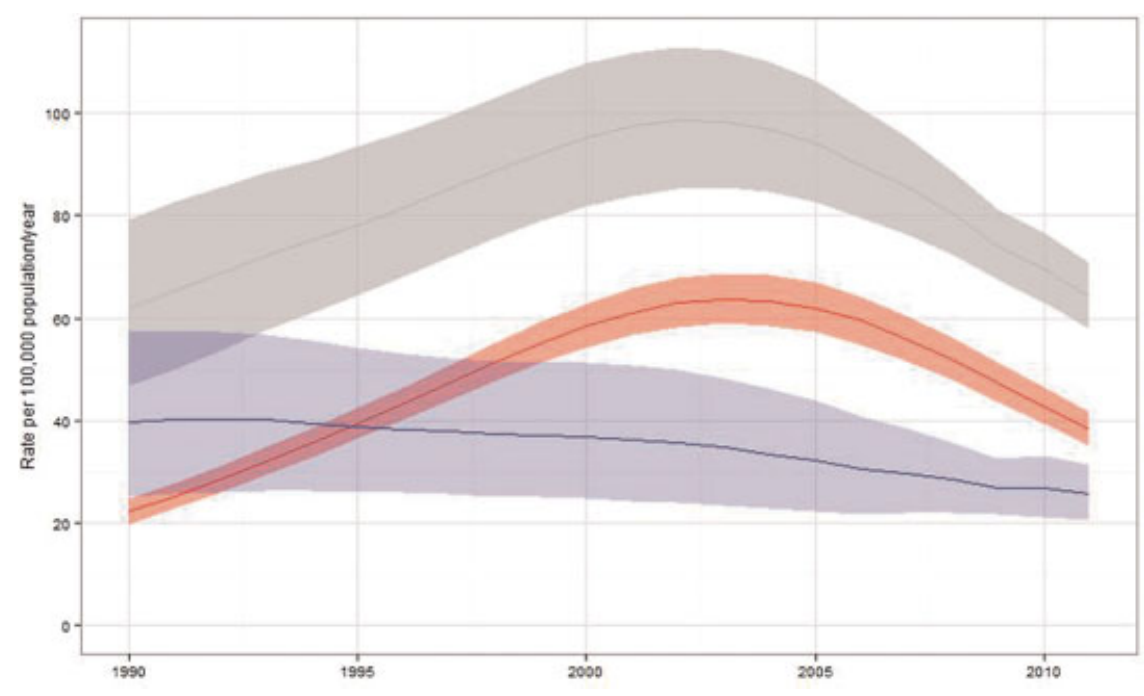

Fig. 4 Trends in tuberculosis (TB) mortality rates in Africa. In HIV-negative people (blue), TB-associated acquired immunodeficiency syndrome (AIDS) deaths (red), total TB deaths (gray). Shaded areas represent uncertainty bands. 

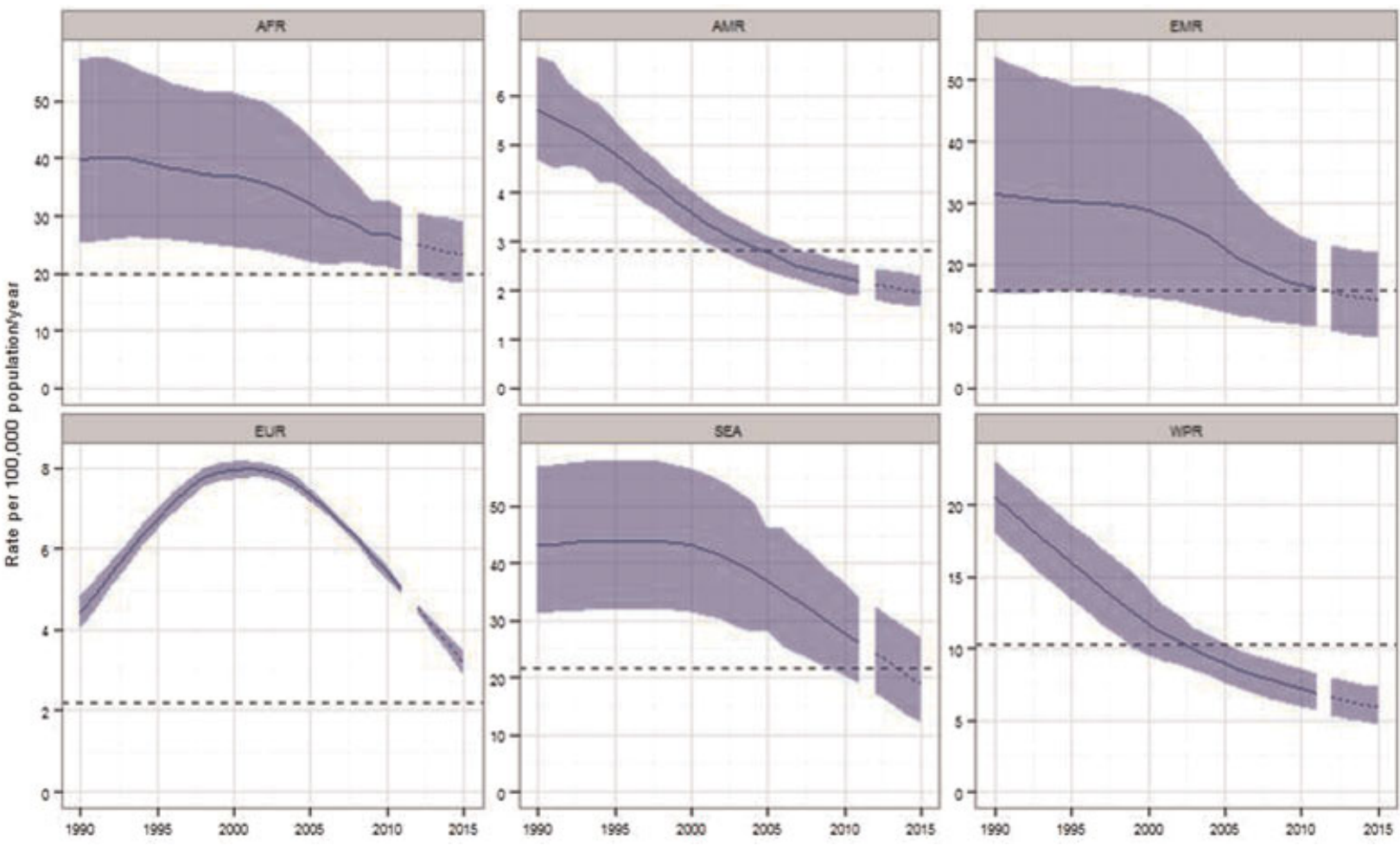

Fig. 5 Trends in estimated tuberculosis (TB) mortality rates excluding human immunodeficiency virus (HIV) during the period 1990 to 2011 and forecast TB mortality rates 2012 to 2015 by World Health Organization (WHO) region. Estimated TB mortality excludes TB deaths among HIVpositive people (which are classified as acquired immunodeficiency syndrome deaths). Shaded areas represent uncertainty bands. The horizontal dashed lines represent the Stop TB Partnership target of a 50\% reduction in the mortality rate by 2015 compared with 1990 . The other dashed lines show projections up to 2015 .
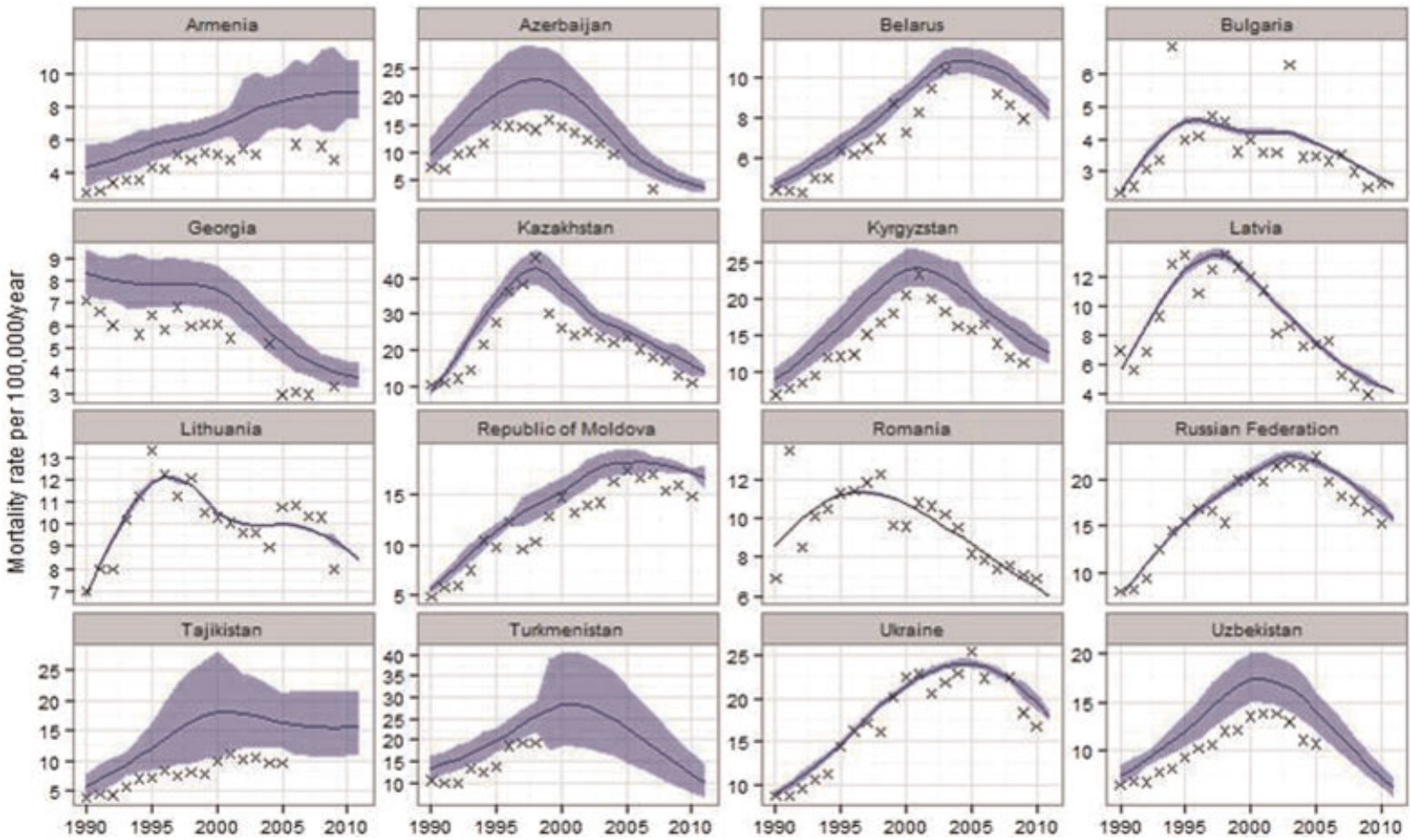

Fig. 6 Trends in tuberculosis (TB) mortality rates (excluding human immunodeficiency virus) in eastern Europe. The X symbol shows raw TB mortality rates obtained from national vital registration systems. The raw data are adjusted for incomplete coverage of deaths and for ill-defined causes of deaths (blue). Shaded areas represent uncertainty bands. 
tuberculosis is rapid, with a marked reduction in life expectancy. ${ }^{45}$ The gap between the 2015 targets and current prevalence rates in these two regions means that the world as a whole is unlikely to meet the target of halving the 1990 prevalence rate by 2015 .

\section{Case Notifications and Treatment Success}

In 2011, 5.7 million new cases of TB were notified by National TB Programmes (NTPs) to WHO, including 0.3 million recurrent episodes of TB after being previously cured of the disease. Among people who were diagnosed with $\mathrm{TB}$ for the first time (new cases), 2.6 million had sputum smear-positive pulmonary TB. India and China accounted for $39 \%$ of the 5.7 million new and recurrent cases of TB that were reported in 2011 (23\% and 16\%, respectively); Southeast Asia and Western Pacific Regions accounted for $60 \%$ of cases globally. African countries accounted for $24 \%$ (one quarter of these cases were from South Africa).

Most cases (88\%) were aged 15 to 64 years. Children (aged $<15$ years) accounted for $<10 \%$ of notified cases in almost all 22 high-burden countries (HBCs) and all WHO regions. The sex ratio (M:F) was 1.7. The reasons for higher TB notification rates in men are poorly understood. ${ }^{46}$ Possible explanations include biological differences between men and women in certain age groups that affect the risk of being infected as well as the risk of infection progressing to active disease, ${ }^{47}$ and differences in the societal roles of men and women that influence their risk of exposure to $\mathrm{TB}$ and access to care (gender differences). ${ }^{48-50}$ The observation that TB notification rates tend to be more equal between men and women in countries with a high prevalence of HIV supports the hypothesis of biological differences (that can be lessened by immunological suppression due to HIV), but other nonbiological factors may play an important role. Variation in the sex ratio among countries may reflect real differences in epidemiology as well as differential access to health care and use of services linked to the NTP. In some settings (e.g., Afghanistan, parts of Iran and Pakistan), the sex ratio is less than 1 , suggesting that nonbiological factors may play a role. In national populationbased surveys of the prevalence of TB disease in Asia the sex ratio has been between around 3 and 4 , suggesting that women access TB care services linked to the NTP to a greater extent than men in some settings or that disease progression in those settings could be slower on average in women.

Globally, $86 \%$ of the new cases in 2010 were successfully treated. The treatment success rate was $78 \%$ in Africa (where there has been steady improvement since 2006), $74 \%$ in the Region of the Americas, and 74\% in the European Region, in the latter case probably due to a high prevalence of drugresistant TB. Treatment success for MDR-TB patients was much lower (to be discussed).

\section{HIV-Associated TB}

The prevalence of HIV coinfection in patients with TB is the highest in the African Region ( $\mathbf{- F i g . ~ 7 ) . ~ T h e ~ A f r i c a n ~ R e g i o n ~}$ accounts for almost $80 \%$ of HIV-positive TB cases worldwide.
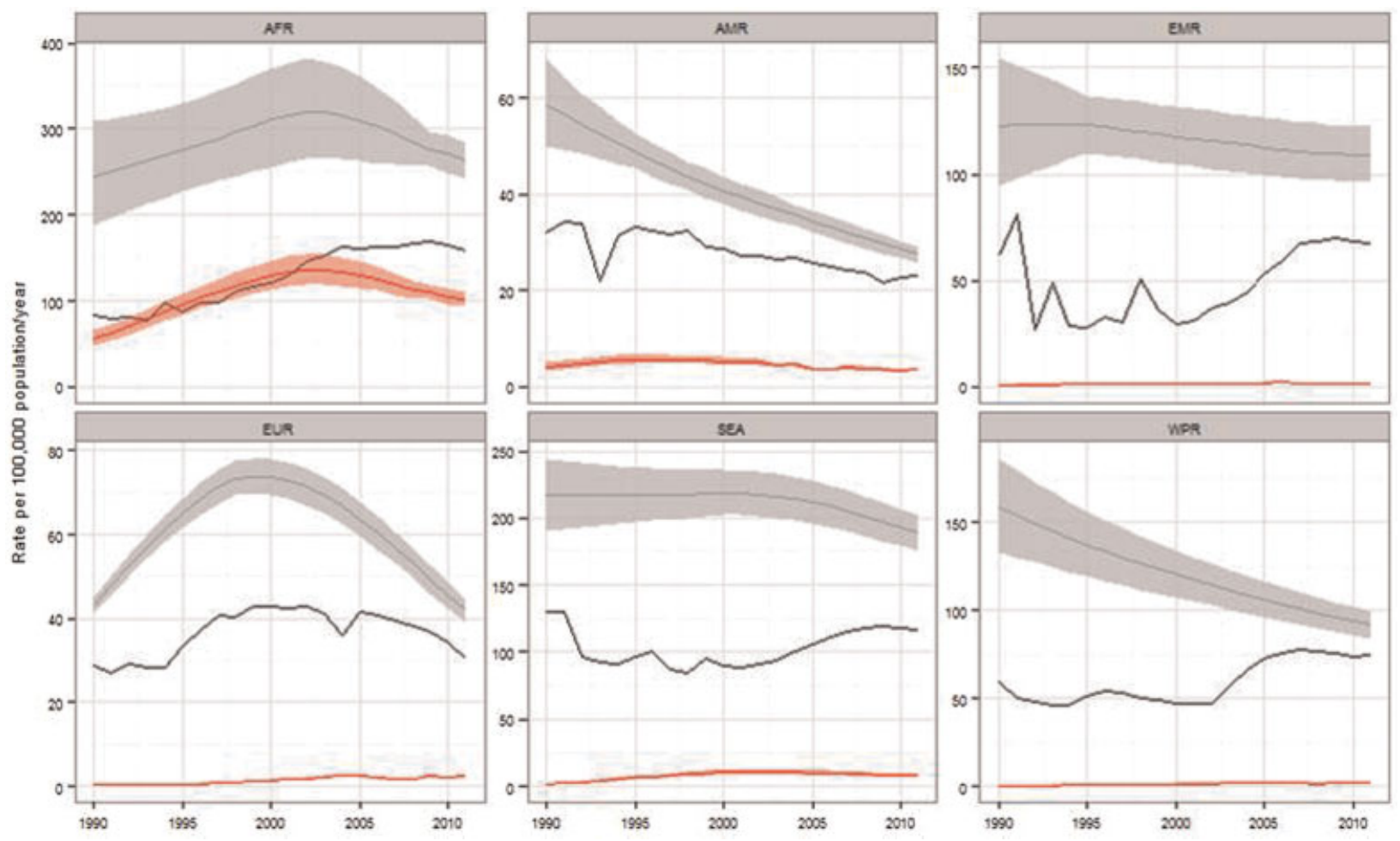

Fig. 7 Global trends in estimated tuberculosis (TB) incidence rates by World Health Organization (WHO) region. Regional trends in estimated incidence rates (all forms of TB) including human immunodeficiency virus (HIV)-negative and HIV-positive TB (gray) and estimated incidence rate of HIV-positive TB (red). The solid black line shows global trends in case notification rates (all forms of TB). Shaded areas represent uncertainty bands. 
Of TB patients with an HIV test result, $44 \%$ tested positive in 2011, ranging from 8\% in Ethiopia to 77\% in Swaziland. Sixtynine percent of patients with TB in Africa and 40\% worldwide had been tested for HIV status in 2011, and among TB patients known to be HIV-positive, $79 \%$ were provided with cotrimoxazole preventive therapy (CPT) and $48 \%$ were started on ART. Among people living with HIV, 3.2 million were reported to have been screened for TB at their latest health visit in 2011, and 0.46 million of those without active TB were provided with isoniazid preventive therapy (IPT).

The coverage of ART for patients with TB who are HIVpositive needs to be improved. The enrollment of $48 \%$ of patients with TB known to be HIV-positive on ART is still low, given WHO's recommendation that ART should be provided to all TB patients living with HIV. Screening for TB among people living with HIV and provision of IPT also need to be increased. Recording and reporting of both these interventions still remains a challenge, and further efforts are needed to improve the tracking of progress nationally and globally.

\section{Multidrug-Resistant TB}

Drug resistance complicates the management of tuberculosis and represents one of the most important emerging challenges in the control of TB worldwide. ${ }^{10,51}$ Resistance develops as a result of inadequate treatment and, contrary to past beliefs, resistant strains can propagate to other individuals in the same manner as drug-susceptible ones. Its diagnosis requires DST of TB strains.

The global surveillance of resistance to the two most important first-line anti-TB drugs-isoniazid and rifampicinor MDR-TB has been coordinated by WHO since $1994 .{ }^{52}$ In 2006, MDR-TB cases infected with strains resistant to further antibiotics were reported to have poor prognosis. XDR-TB was defined for MDR-TB cases with additional resistance to the two most effective classes of second-line drugs-the fluoroquinolones and second-line injectable drugs (amikacin, kanamycin, and capreomycin). ${ }^{53}$ XDR-TB cases with even broader resistance patterns have been reported in more recent years from different countries. ${ }^{54-56}$

Reliable data on levels of MDR-TB are available from $70 \%$ of WHO's 194 Member States. ${ }^{1}$ These data derive from specially executed surveys or routine surveillance systems that aim to achieve representativeness in a given setting and the laboratory procedures of which are quality controlled internationally. It is estimated that, on a global level, 3.7\% (95\% confidence interval: 2.1 to $5.2 \%)$ of TB treatment-naive cases and $20 \%$ ( 13 to $26 \%$ ) of previously treated TB cases have MDRTB ( - Fig. 8 shows the percentage of new cases with MDR-TB at country level). By the end of 2011, XDR-TB had been reported by 84 countries; on average $9.0 \%$ (6.7 to $11.2 \%$ ) of MDR-TB cases had XDR-TB. These estimates imply that in 2011, among notified patients with pulmonary TB, there were an estimated 310,000 (range: 220,000 to 400,000 ) MDR-TB cases and $\sim 25,000$ XDR-TB cases. However, if one considers all estimated cases of TB, nearly half a million MDR-TB cases may emerge annually. More than half of these cases would be expected in China, India, and the Russian Federation alone. TB patients from countries of the former Soviet Union have the highest risk of MDR-TB in the world, and one third to one half of TB cases presenting for treatment in several countries, including in the Russian Federation and Belarus, are infected with MDR-TB strains.

The management of drug resistance is based (1) on preventing the emergence of resistant strains through adequate basic treatment of patients with $\mathrm{TB},(2)$ on the early detection and proper treatment of existing patients with MDR-TB to

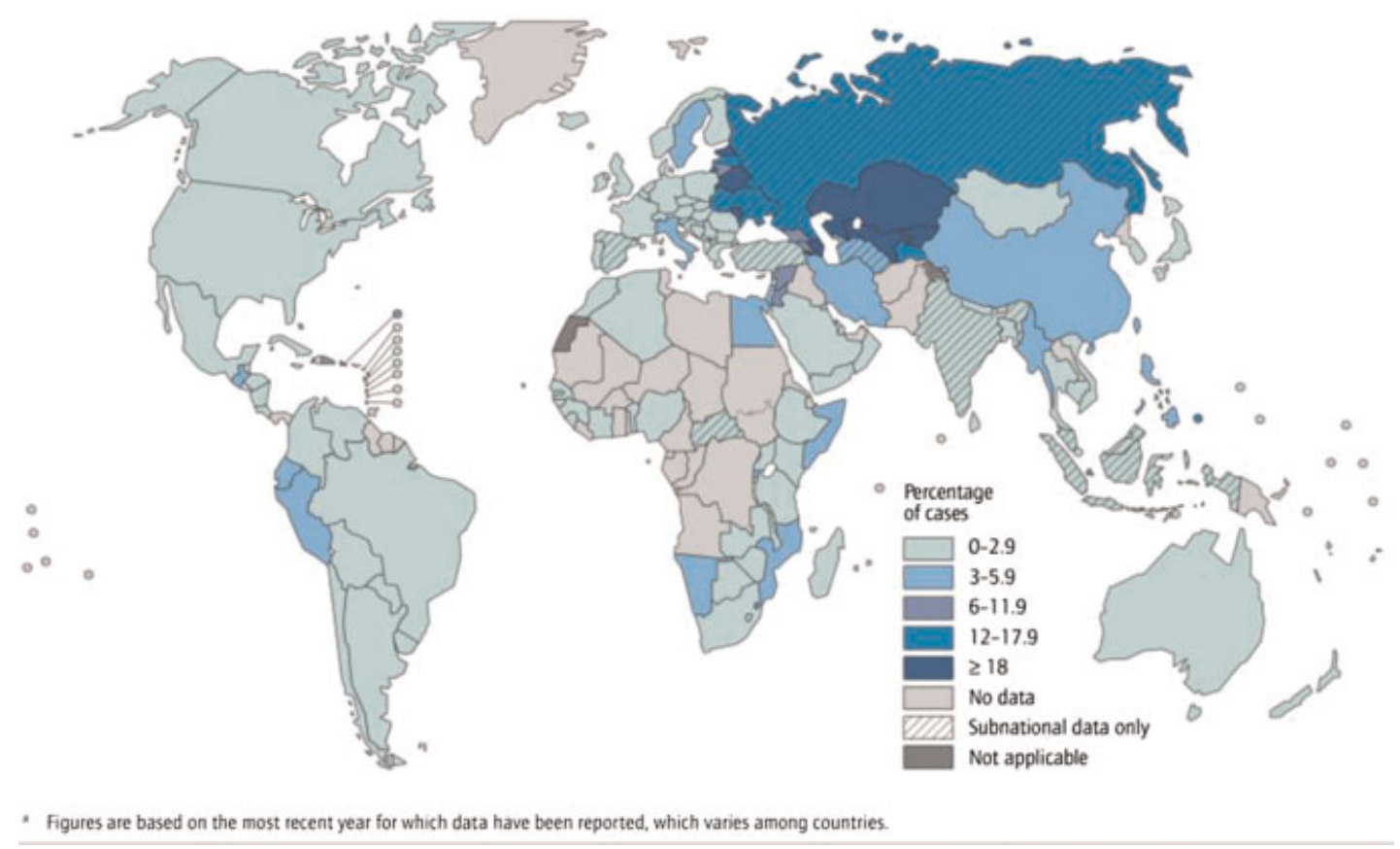

Fig. 8 Proportion of multidrug resistance in new tuberculosis cases. ${ }^{a}$ 


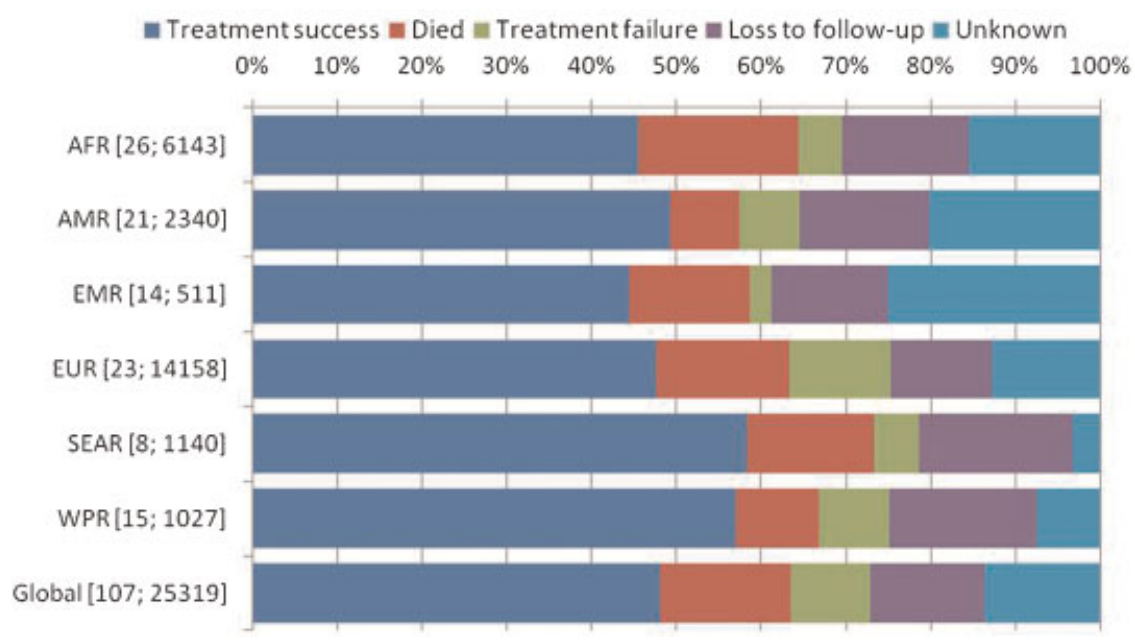

Fig. 9 Treatment outcomes for patients diagnosed with multidrug-resistant tuberculosis (MDR-TB) in countries, 2009 cohorts, by World Health Organization (WHO) region. The number of countries reporting outcomes for at least one case, followed by total cases with outcome data, shown beside each bar.

stop transmission, and (3) on measures to limit transmission through infection control. The management of drug-resistant $\mathrm{TB}$ requires that the necessary program components are in place to ensure that patient care is supportive, comprehensive, and effective.

Most drug-susceptible TB cases can usually be treated with a standard course of combination chemotherapy of 6 months duration. In 2010, treatment success was reported in $86 \%$ of over 5 million previously untreated patients with TB worldwide. ${ }^{8}$ Patients may not finish their treatment successfully as a result of death, but also because of treatment failure or loss to follow-up. In these two latter situations, the risk of drug resistance is high. In most MDR-TB cases, a treatment duration of 20 months is recommended and requires daily administration of drugs that are more expensive, more toxic, and less effective than those used to treat drug-susceptible forms of $\mathrm{TB}^{57}$ Among patients with MDR-TB started on treatment in 2009 only $48 \%$ were successfully treated, as a result of a high frequency of death (15\%) and loss to follow-up or evaluation (28\%) (-Fig. 9). Among a subset of 200 patients with XDR-TB in 14 countries, treatment success was only $33 \%$ overall and $26 \%$ died.

Diagnostic testing for drug-resistant TB remains problematic as a result of low capacity to undertake the required laboratory DST and also to transmit rapidly the data on test results to the centers responsible for public health reporting. Suboptimal coverage of DST due to the lack of laboratory capacity in many countries is one of the main reasons why the number of people who are diagnosed with MDR-TB remains low. Globally, only 6\% of previously treated TB cases, who are at a particular risk of drug resistance, were known to have had DST for isoniazid and rifampicin in 2011. Among patients with TB who were confirmed to have MDR-TB in 2011, 23\% were reported to have DST also for both fluoroquinolones and second-line injectable drugs, but coverage varies greatly between countries.
Globally, just under 60,000 cases of MDR-TB were notified to WHO in 2011, mostly by European countries and South Africa. This represented $\sim 19 \%$ of the estimated cases of MDRTB that could be detected were access to DST made universally available to all reported patients with TB. By the end of June 2012, new diagnostics based on molecular techniques have been deployed in 67 low- and middle-income countries, ${ }^{1,58,59}$ and they should make it possible in future for more persons with drug-resistant disease to be detected earlier in the course of their disease, thus improving outcomes. Patients with MDR-TB may be cared for as outpatients or in hospitals, usually secondary or tertiary facilities. WHO recommends that where possible patients with MDR-TB be treated using ambulatory care rather than models of care based principally on hospitalization. This is important given that treatment at home is generally more acceptable to patients, and the risk of infection to other patients, particularly those debilitated by other medical conditions such as HIV, will be reduced.

\section{Can TB Be Eliminated by 2050?}

TB can be controlled by preventing infection, stopping progression from infection to active disease, and detecting rapidly and treating active disease ${ }^{60,61}$ (-Fig. 10). To date, only Bacille-Calmette Guérin (BCG) vaccination (provided to more than $80 \%$ of the annual birth cohort) and treatment of active TB using first-line drugs have been implemented on a large scale. ${ }^{62,63}$ With these interventions resulting in a global decline of some 1.5 to $2 \%$ per year, elimination (defined as an annual incidence of new cases of less than 1 per million population) will not be achieved by $2050^{64}$ (-Fig. 11).

In countries with multiple sources of TB data and effective TB control programs (e.g., China, Cambodia), the annual decline in estimated TB incidence is estimated at $~ 3$ to $4 \%$ / year. Sources of data include measurements of TB prevalence 


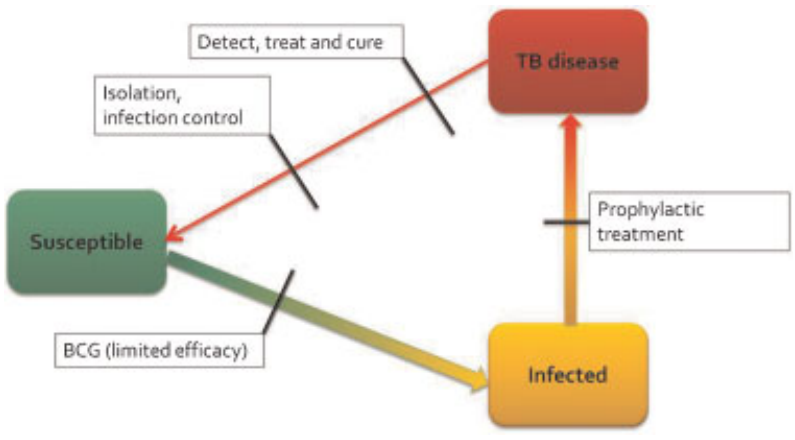

Fig. 10 Principles for stopping tuberculosis (TB) transmission. TB control is based on preventing susceptible individuals from becoming infected using vaccination, preventing infected individuals from developing the disease using prophylactic treatment, preventing individuals with TB from having contact with susceptible individuals through early detection and cure, isolation, and infection control measures.

in repeat surveys and annual measurements of TB mortality through vital registration (VR) systems. The reasons for such declines in incidence go beyond the impact of biomedical interventions to control $\mathrm{TB}$ and include economic growth with improvements in living conditions, nutrition, and housing, among other factors.

The fastest declines in TB incidence at the national level have been observed in countries of Western Europe in the late 1940 s and 1950s (i.e., the 2 decades after World War II), when TB declined at $\sim 8$ to $10 \% /$ year $^{65}$ ( - Fig. 11). A combination of enabling factors included a rapid shift from the pre-chemotherapy era to a chemotherapy era, universal health insurance and social protection, a high level of population coverage of quality health services, and consistent economic growth. Faster declines in TB incidence were observed between 1952 and 1970 in an intensively studied population of Alaskan natives, ${ }^{66}$ but such declines have never been achieved on a nationwide basis. As in the immediate postWorld War II period, a paradigm shift in the tools available for TB control is now needed, in the context of universal health coverage. ${ }^{67}$ Incidence would need to decline as fast as $20 \%$ / year for the elimination target to be achieved by 2050 .

To accelerate progress, wider application of existing interventions combined with development and implementation of new drugs, vaccines, and diagnostic tools is required, as set out in the Stop TB Strategy and the Global Plan to Stop TB. ${ }^{12,13}$

The 2050 target of TB elimination is most likely to be achieved if latent infection and disease are treated. ${ }^{68}$ Randomized controlled trials have shown that up to 12 months of daily IPT for treatment of latent infection confers 25 to $92 \%$ protection against developing active $\mathrm{TB}$, with results toward the upper end of this range when patients adhere fully to the treatment regimen. ${ }^{69}$ Isoniazid is also a relatively safe drug (the main side-effect is hepatitis, which occurs in around 1\% of patients), and the exceptionally high risk of TB among people coinfected with Mycobacterium tuberculosis and HIV is a reason for promoting much greater use in settings with a high prevalence of HIV. ${ }^{70,71}$ To date, however, IPT is not widely used. In 2011, only a small proportion of HIV-positive people without active TB were treated with IPT.

Besides IPT, there is considerable scope to expand interventions to reduce TB-related mortality in people who are HIV-positive. ART decreases the incidence of TB among people living with HIV (although more research is needed to understand the impact of large-scale ART programs on TB epidemics) and reduces mortality. CPT for patients with TB who are HIV-positive reduces mortality. ${ }^{72,73}$ In 2011 69\% of patients with TB in the African Region knew their HIV status from provider-initiated HIV testing and counseling, ${ }^{72,74}$ and 0.26 million of the estimated 1.1 million HIV-positive TB cases were started on ART. ${ }^{1}$ Recent expansion of TB control in areas where the prevalence of HIV is high has also exposed a neglect of the basic principles of infection control, where immunosuppressed patients have been exposed to patients with

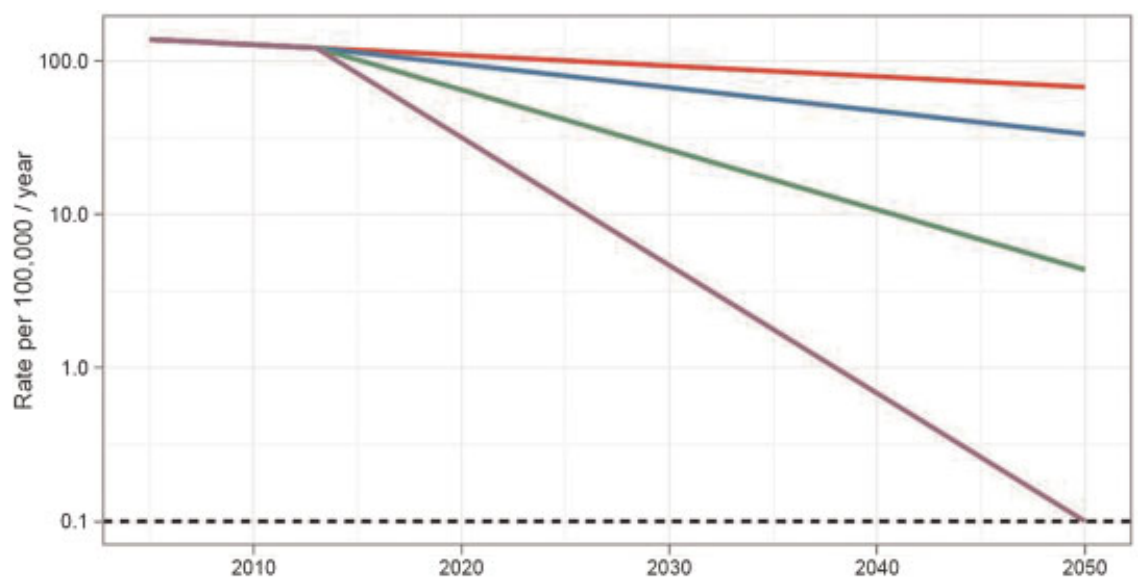

Fig. 11 Projected trends in tuberculosis (TB) incidence from 2013 to 2050. The $y$-axis is on a log scale. The global decline in estimated TB incidence during the period 2005 to 2010 is 1.6\%/year. In countries with the best performance over the past decade (e.g., Cambodia, China), incidence is declining at 3 to $4 \%$ year. In countries with all-time best performance (e.g., Western European countries after World War II), incidence declined at an average rate of $\sim 8$ to $10 \% / y e a r$. The decline needed to reach elimination by 2050 is $19 \%$ /year from 2013 onward; such a decline has never been observed on a nationwide basis. 
active TB in clinics and hospitals. ${ }^{75,76} \mathrm{~A}$ reappraisal of infection control policies and their implementation in hospitals and congregate settings is required in many countries.

Provision of diagnosis and treatment for cases of MDR-TB is mostly confined to the European Region, North America, and South Africa. ${ }^{77}$ Urgent improvements in the provision of services for laboratory culture and DST, new rapid drug susceptibility tests, as well as treatment are needed in many countries. The emergence of XDR-TB ${ }^{78,79}$ has reinforced the need for updated plans to improve the performance of TB control, including prevention of resistance amplification, transmission of resistant strains, and the capacity to diagnose and treat adequately TB drug resistance. ${ }^{80-82}$

In addition to scaling up interventions related to treatment of latent infection, TB/HIV, and MDR-TB, the Stop TB Strategy also emphasizes the importance of engaging all care providers in both the public and the non-state sectors, to shorten delays to diagnosis, and to ensure that treatment for all patients (in both the public and the non-state sector) meets international standards. ${ }^{83}$ This means engaging medical services in prisons and the armed forces; private clinics, nongovernmental organizations, faith-based organizations, mission services, and hospitals; and clinics in the corporate sector. ${ }^{84-88}$

Beyond wider use of existing tools, research and development related to new drugs, new diagnostics, and new vaccines has accelerated in recent years. ${ }^{1,6,63,64,89-92}$ For example, several pharmaceutical companies have embarked on the development of new anti-TB drugs, which may shorten treatment duration to 4 months or less; two drugs targeting MDR-TB are now in advanced phases of clinical trials. New diagnostics for rapid detection of MDR-TB that have become available recently have been endorsed by WHO, and promising rapid tests are being developed. ${ }^{1}$ The challenge will be to incorporate new tools into TB control practices while also strengthening overall health systems and ensuring wider access to prevention, diagnosis, and treatment.

Finally, recognition that TB depends largely upon social and economic determinants of ill health is crucial to achieving full control and elimination. Factors such as smoking, alcohol abuse, diabetes, indoor air pollution, and malnutrition, like HIV, are affecting TB epidemiology and impeding faster progress toward TB control. ${ }^{6,93}$ At the population level, these various factors seem to contribute to considerable proportions of TB cases worldwide and to differing extents by region. Therefore, preventive strategies may result in remarkable outcomes among certain vulnerable groups, such as people with diabetes and those infected with HIV. Likewise, reductions in levels of smoking, alcohol abuse, malnutrition, and indoor air pollution will likely be associated with reductions in TB infection and disease. Ultimately, broad education of people, promotion of good health, universal health care coverage, ${ }^{94}$ and povertyreduction strategies will have an effect on the TB epidemic by progressively removing individuals from the vulnerable pool.

\section{Conclusions}

Progress in our understanding of TB epidemiology and the availability of effective diagnosis and treatments have resulted in major gains over the past few decades. Recent discoveries and new tools have prompted a more optimistic view of the future course of the TB pandemic. Nevertheless, the numbers of new TB cases that occur each year and the number of people who die from TB are still high, particularly in poor and otherwise disadvantaged populations. ${ }^{95}$ To achieve global targets set for 2015 and 2050, major and urgent scaling up of the interventions and approaches included in the Stop TB Strategy is needed in most countries. ${ }^{6,63}$ A post-2015 global strategy to control TB will necessarily include the successful development and application of new drugs, diagnostics, and vaccines, ${ }^{96}$ as well as a clearer understanding of the impact of social and economic determinants of ill health. An intervention to reduce the risk of TB in the large pool of infected individuals (vaccine or chemoprophylaxis) must also be initiated to accelerate the decline in TB incidence.

Overall, we are at a crossroads in TB care and control: new technological advances are finally becoming available after decades of stagnation, and most countries have adopted sound approaches to the many existing challenges. Increased investments, both by endemic countries themselves and, where needed, from international sources are necessary to sustain the gains, consolidate the efforts, and pursue bolder targets toward elimination in the coming decades.

\section{Acknowledgments}

We sincerely thank Matteo Zignol for his contribution to the section on drug-resistant tuberculosis.

\section{Copyright}

(c) World Health Organization 2013. All rights reserved. The World Health Organization has granted the Publisher permission for the reproduction of this article.

\section{References}

1 WHO. Global tuberculosis report 2012. Geneva, Switzerland: WHO; 2012

2 WHO, ed. The Global Burden of Disease: 2004 Update. Geneva, Switzerland: World Health Organization; 2008

3 Lopez AD, Mathers CD, Ezzati M, Jamison DT, Murray CJ. Global and regional burden of disease and risk factors, 2001: systematic analysis of population health data. Lancet 2006;367(9524): $1747-1757$

4 Miller TL, McNabb SJ, Hilsenrath P, Pasipanodya J, Weis SE. Personal and societal health quality lost to tuberculosis. PLoS ONE 2009;4 (4): $\mathrm{e} 5080$

5 Zumla A, Mwaba P, Huggett J, Kapata N, Chanda D, Grange J. Reflections on the white plague. Lancet Infect Dis 2009;9(3): 197-202

6 Lienhardt C, Glaziou P, Uplekar M, Lönnroth K, Getahun H, Raviglione M. Global tuberculosis control: lessons learnt and future prospects. Nat Rev Microbiol 2012;10(6):407-416

7 Murray CJ, Dejonghe E, Chum HJ, Nyangulu DS, Salomao A, Styblo K. Cost effectiveness of chemotherapy for pulmonary tuberculosis in three sub-Saharan African countries. Lancet 1991;338(8778): 1305-1308

8 Dye C, Floyd K. Tuberculosis. In: Jamison DT, Breman JG, Measham AR, et al, eds. Disease Control Priorities in Developing Countries. Washington, DC: Oxford University Press; 2006:289-309 
9 Dye C, Bassili A, Bierrenbach AL, et al. Measuring tuberculosis burden, trends, and the impact of control programmes. Lancet Infect Dis 2008;8(4):233-243

10 Raviglione MC, Uplekar MW. WHO's new Stop TB Strategy. Lancet 2006;367(9514):952-955

11 Korenromp EL, Glaziou P, Fitzpatrick C, et al. Implementing the global plan to stop TB, 2011-2015-optimizing allocations and the Global Fund's contribution: a scenario projections study. PLoS ONE 2012;7(6):e38816

12 Raviglione MC. The Global Plan to Stop TB, 2006-2015. Int J Tuberc Lung Dis 2006;10(3):238-239

13 Raviglione MC. The new Stop TB Strategy and the Global Plan to Stop TB, 2006-2015. Bull World Health Organ 2007; 85(5):327

14 Van Hest NA, Story A, Grant AD, Antoine D, Crofts JP, Watson JM. Record-linkage and capture-recapture analysis to estimate the incidence and completeness of reporting of tuberculosis in England 1999-2002. Epidemiol Infec 2008;136(12):1606-1616

15 Bierrenbach AL, Stevens AP, Gomes AB, et al. [Impact on tuberculosis incidence rates of removal of repeat notification records.] Rev Saude Publica 2007;41(Suppl 1):67-76

16 Dye C, Ottmani S, Laasri L, Bencheikh N. The decline of tuberculosis epidemics under chemotherapy: a case study in Morocco. Int J Tuberc Lung Dis 2007;11(11):1225-1231

17 Mansoer JSS, Scheele S, Floyd K, Dye C, Sitienei J, Williams B. New methods for estimating the tuberculosis case detection rate in high-HIV prevalence countries: the example of Kenya. Bull World Health Organ 2009;87(3):186-192, 192A-192B

18 Botha E, den Boon S, Lawrence KA, et al. From suspect to patient: tuberculosis diagnosis and treatment initiation in health facilities in South Africa. Int J Tuberc Lung Dis 2008;12(8):936-941

19 Dye C, Scheele S, Dolin P, Pathania V, Raviglione MC. Consensus statement. Global burden of tuberculosis: estimated incidence, prevalence, and mortality by country. WHO Global Surveillance and Monitoring Project. JAMA 1999;282(7):677-686

20 Uplekar M, Pathania V, Raviglione M. Private practitioners and public health: weak links in tuberculosis control. Lancet 2001;358 (9285):912-916

21 Meintjes G, Schoeman H, Morroni C, Wilson D, Maartens G. Patient and provider delay in tuberculosis suspects from communities with a high HIV prevalence in South Africa: a cross-sectional study. BMC Infect Dis 2008;8:72

22 Véron LJ, Blanc LJ, Suchi M, Raviglione MC. DOTS expansion: will we reach the 2005 targets? Int J Tuberc Lung Dis 2004;8(1): 139-146

23 Baussano I, Bugiani M, Gregori D, et al. Undetected burden of tuberculosis in a low-prevalence area. Int J Tuberc Lung Dis 2006;10(4):415-421

24 Borgdorff MW, Glynn JR, Vynnycky E. Using capture-recapture methods to study recent transmission of tuberculosis. Int J Epidemiol 2004;33(4):905-906, author reply 907

25 Cailhol J, Che D, Jarlier V, Decludt B, Robert J. Incidence of tuberculous meningitis in France, 2000: a capture-recapture analysis. Int J Tuberc Lung Dis 2005;9(7):803-808

26 Crofts JP, Pebody R, Grant A, Watson JM, Abubakar I. Estimating tuberculosis case mortality in England and Wales, 2001-2002. Int J Tuberc Lung Dis 2008;12(3):308-313

27 WHO, ed. Tuberculosis Prevalence Surveys: A Handbook. Geneva, Switzerland: WHO; 2011

28 Glaziou P, van der Werf MJ, Onozaki I, et al. Tuberculosis prevalence surveys: rationale and cost. Int J Tuberc Lung Dis 2008;12(9): 1003-1008

29 Soemantri S, Senewe FP, Tjandrarini DH, et al. Three-fold reduction in the prevalence of tuberculosis over 25 years in Indonesia. Int J Tuberc Lung Dis 2007;11(4):398-404

30 Dye C, Fengzeng Z, Scheele S, Williams B. Evaluating the impact of tuberculosis control: number of deaths prevented by short-course chemotherapy in China. Int J Epidemiol 2000;29(3):558-564
31 Tupasi TE, Radhakrishna S, Rivera AB, et al. The 1997 Nationwide Tuberculosis Prevalence Survey in the Philippines. Int J Tuberc Lung Dis 1999;3(6):471-477

32 Hong YP, Kim SJ, Lew WJ, Lee EK, Han YC. The seventh nationwide tuberculosis prevalence survey in Korea, 1995. Int J Tuberc Lung Dis 1998;2(1):27-36

33 Korenromp EL, Bierrenbach AL, Williams BG, Dye C. The measurement and estimation of tuberculosis mortality. Int J Tuberc Lung Dis 2009;13(3):283-303

34 WHO. Guidelines for Surveillance of Drug Resistance in Tuberculosis. Geneva, Switzerland: WHO; 2009

35 Riley RL. The contagiosity of tuberculosis. Schweiz Med Wochenschr 1983;113(3):75-79

36 WHO. Tuberculosis Fact Sheet. Geneva, Switzerland: WHO; 2012

37 Borgdorff MW, Sebek M, Geskus RB, Kremer K, Kalisvaart N, van Soolingen $\mathrm{D}$. The incubation period distribution of tuberculosis estimated with a molecular epidemiological approach. Int J Epidemiol 2011;40(4):964-970

38 Vynnycky E, Fine PE. Lifetime risks, incubation period, and serial interval of tuberculosis. Am J Epidemiol 2000;152(3):247-263

39 Tiemersma EW, van der Werf MJ, Borgdorff MW, Williams BG, Nagelkerke NJ. Natural history of tuberculosis: duration and fatality of untreated pulmonary tuberculosis in HIV negative patients: a systematic review. PLoS ONE 2011;6(4):e17601

40 Straetemans M, Glaziou P, Bierrenbach AL, Sismanidis C, van der Werf MJ. Assessing tuberculosis case fatality ratio: a meta-analysis. PLoS ONE 2011;6(6):e20755

41 Shilova MV, Dye C. The resurgence of tuberculosis in Russia. Philos Trans R Soc Lond B Biol Sci 2001;356(1411):1069-1075

42 Glaziou P, Floyd K, Korenromp EL, et al. Lives saved by tuberculosis control and prospects for achieving the 2015 global target for reducing tuberculosis mortality. Bull World Health Organ 2011;89 (8):573-582

43 Straetemans M, Bierrenbach AL, Nagelkerke N, Glaziou P, van der Werf MJ. The effect of tuberculosis on mortality in HIV positive people: a meta-analysis. PLoS ONE 2010;5(12):e15241

44 Williams BG, Granich R, De Cock KM, Glaziou P, Sharma A, Dye C. Antiretroviral therapy for tuberculosis control in nine African countries. Proc Natl Acad Sci USA 2010;107(45):19485-19489

45 Corbett EL, Charalambous S, Moloi VM, et al. Human immunodeficiency virus and the prevalence of undiagnosed tuberculosis in African gold miners. Am J Respir Crit Care Med 2004;170(6):673679

46 Ottmani SE, Uplekar MW. Gender and TB: pointers from routine records and reports. Int J Tuberc Lung Dis 2008;12(7):827-828

47 Thorson A, Long NH, Larsson LO. Chest X-ray findings in relation to gender and symptoms: a study of patients with smear positive tuberculosis in Vietnam. Scand J Infect Dis 2007;39(1):33-37

48 Borgdorff MW, Nagelkerke NJ, Dye C, Nunn P. Gender and tuberculosis: a comparison of prevalence surveys with notification data to explore sex differences in case detection. Int J Tuberc Lung Dis 2000;4(2):123-132

49 Connolly M, Nunn P. Women and tuberculosis. World Health Stat Q 1996;49(2):115-119

50 Somma D, Thomas BE, Karim F, et al. Gender and socio-cultural determinants of TB-related stigma in Bangladesh, India, Malawi and Colombia. Int J Tuberc Lung Dis 2008;12(7):856-866

51 WHO. Towards Universal Access to Diagnosis and Treatment of Multidrug-Resistant and Extensively Drug-Resistant Tuberculosis by 2015. WHO Progress Report 2011. Geneva, Switzerland: WHO; 2011. Report No.: WHO/HTM/TB/2011.3

52 Zignol M, van Gemert W, Falzon D, et al. Surveillance of antituberculosis drug resistance in the world: an updated analysis, 2007-2010. Bull World Health Organ 2012;90(2):111-119D

53 WHO. WHO Global Task Force Outlines Measures to Combat XDR-TB Worldwide. Geneva, Switzerland: WHO; 2006. Available at: www. who.int/mediacentre/news/notes/2006/np29/. Accessed January 18,2013 
54 Velayati AA, Masjedi MR, Farnia P, et al. Emergence of new forms of totally drug-resistant tuberculosis bacilli: super extensively drugresistant tuberculosis or totally drug-resistant strains in Iran. Chest 2009;136(2):420-425

55 Migliori GB, De Iaco G, Besozzi G, Centis R, Cirillo DM. First tuberculosis cases in Italy resistant to all tested drugs. Euro Surveill 2007;12(5):E070517.1

56 Udwadia ZF, Amale RA, Ajbani KK, Rodrigues C. Totally drugresistant tuberculosis in India. Clin Infect Dis 2012;54(4):579-581

57 WHO. Guidelines for the Programmatic Management of DrugResistant Tuberculosis, 2011 Update. Geneva, Switzerland: WHO; 2011

58 Meyer-Rath G, Schnippel K, Long L, et al. The impact and cost of scaling up GeneXpert MTB/RIF in South Africa. PLoS ONE 2012;7 (5):e36966

59 Evans CA. GeneXpert-a game-changer for tuberculosis control? PLoS Med 2011;8(7):e1001064

60 Dye C, Garnett GP, Sleeman K, Williams BG. Prospects for worldwide tuberculosis control under the WHO DOTS strategy. Directly observed short-course therapy. Lancet 1998;352(9144):1886-1891

61 Dye C, Watt CJ, Bleed DM, Hosseini SM, Raviglione MC. Evolution of tuberculosis control and prospects for reducing tuberculosis incidence, prevalence, and deaths globally. JAMA 2005;293(22): 2767-2775

62 Lönnroth K, Castro KG, Chakaya JM, et al. Tuberculosis control and elimination 2010-50: cure, care, and social development. Lancet 2010;375(9728):1814-1829

63 Raviglione M, Marais B, Floyd K, et al. Scaling up interventions to achieve global tuberculosis control: progress and new developments. Lancet 2012;379(9829):1902-1913

64 Lönnroth K, Raviglione M. Global epidemiology of tuberculosis: prospects for control. Semin Respir Crit Care Med 2008;29(5): 481-491

65 Raviglione MC, Sudre P, Rieder HL, Spinaci S, Kochi A. Secular trends of tuberculosis in western Europe. Bull World Health Organ 1993;71(3-4):297-306

66 Grzybowski S, Styblo K, Dorken E. Tuberculosis in Eskimos. Tubercle 1976;57(4, Suppl):S1-S58

67 WHO. Health Financing for Universal Coverage. Geneva, Switzerland: WHO; 2012

68 Dye C, Williams BG. Eliminating human tuberculosis in the twenty-first century. J R Soc Interface 2008;5(23):653-662

69 Sterling TR. New approaches to the treatment of latent tuberculosis. Semin Respir Crit Care Med 2008;29(5):532-541

70 Woldehanna S, Volmink J. Treatment of latent tuberculosis infection in HIV infected persons. Cochrane Database Syst Rev 2004;(1): CD000171

71 Churchyard GJ, Scano F, Grant AD, Chaisson RE. Tuberculosis preventive therapy in the era of HIV infection: overview and research priorities. J Infect Dis 2007;196(Suppl 1):S52-S62

72 Harries AD, Zachariah R, Lawn SD. Providing HIV care for coinfected tuberculosis patients: a perspective from sub-Saharan Africa. Int J Tuberc Lung Dis 2009;13(1):6-16

73 Grimwade K, Sturm AW, Nunn AJ, Mbatha D, Zungu D, Gilks CF. Effectiveness of cotrimoxazole prophylaxis on mortality in adults with tuberculosis in rural South Africa. AIDS 2005;19(2):163-168

74 WHO and UNAIDS issue new guidance on HIV testing and counselling in health facilities, 2007. http://www.who.int/mediacentre/ news/releases/2007/pr24/en/index.html. Accessed January 12, 2013

75 Bock NN, Jensen PA, Miller B, Nardell E. Tuberculosis infection control in resource-limited settings in the era of expanding HIV care and treatment. J Infect Dis 2007;196(Suppl 1):S108-S113

76 Wells CD, Cegielski JP, Nelson LJ, et al. HIV infection and multidrugresistant tuberculosis: the perfect storm. J Infect Dis 2007;196 (Suppl 1):S86-S107
77 WHO, ed. Global Tuberculosis Control 2009: Surveillance, Planning, Financing. Geneva, Switzerland: WHO; 2009

78 Shah NS, Wright A, Bai GH, et al. Worldwide emergence of extensively drug-resistant tuberculosis. Emerg Infect Dis 2007;13(3):380-387

79 Migliori GB, Loddenkemper R, Blasi F, Raviglione MC. 125 years after Robert Koch's discovery of the tubercle bacillus: the new XDR-TB threat. Is "science" enough to tackle the epidemic? EurRespir J 2007;29(3):423-427

80 Manissero D, Fernandez de la Hoz K. Surveillance methods and case definition for extensively drug resistant TB (XDR-TB) and relevance to Europe: summary update. Euro Surveill 2006;11(11): E061103.1

81 Raviglione M. XDR-TB: entering the post-antibiotic era? Int J Tuberc Lung Dis 2006;10(11):1185-1187

82 Raviglione MC, Smith IM. XDR tuberculosis-implications for global public health. N Engl J Med 2007;356(7):656-659

83 Hopewell PC, Pai M, Maher D, Uplekar M, Raviglione MC. International standards for tuberculosis care. Lancet Infect Dis 2006;6 (11):710-725

84 Lönnroth K, Uplekar M, Arora VK, et al. Public-private mix for DOTS implementation: what makes it work? Bull World Health Organ 2004;82(8):580-586

85 Ambe G, Lönnroth K, Dholakia Y, et al. Every provider counts: effect of a comprehensive public-private mix approach for TB control in a large metropolitan area in India. Int J Tuberc Lung Dis 2005;9(5):562-568

86 Lönnroth K, Uplekar M. Invest in breaking the barriers of publicprivate collaboration for improved tuberculosis care. Bull World Health Organ 2005;83(7):558-559

87 Floyd K, Arora VK, Murthy KJ, et al. Cost and cost-effectiveness of PPM-DOTS for tuberculosis control: evidence from India. Bull World Health Organ 2006;84(6):437-445

88 Pantoja A, Floyd K, Unnikrishnan KP, et al. Economic evaluation of public-private mix for tuberculosis care and control, India. Part 1: Socio-economic profile and costs among tuberculosis patients. Int J Tuberc Lung Dis 2009;13(6):698-704

89 Pai M, O'Brien R. New diagnostics for latent and active tuberculosis: state of the art and future prospects. Semin Respir Crit Care Med 2008;29(5):560-568

90 Ly LH, McMurray DN. Tuberculosis: vaccines in the pipeline. Expert Rev Vaccines 2008;7(5):635-650

91 Lienhardt C, Raviglione M, Spigelman M, et al. New drugs for the treatment of tuberculosis: needs, challenges, promise, and prospects for the future. J Infect Dis 2012;205(Suppl 2): S241-S249

92 Nicolau I, Ling D, Tian L, Lienhardt C, Pai M. Research questions and priorities for tuberculosis: a survey of published systematic reviews and meta-analyses. PLoS ONE 2012;7(7): e42479

93 Lönnroth K, Jaramillo E, Williams BG, Dye C, Raviglione M. Drivers of tuberculosis epidemics: the role of risk factors and social determinants. Soc Sci Med 2009;68(12):2240-2246

94 Moreno-Serra R, Smith PC. Does progress towards universal health coverage improve population health? Lancet 2012;380 (9845):917-923

95 Squire SB, Obasi A, Nhlema-Simwaka B. The Global Plan to Stop TB: a unique opportunity to address poverty and the Millennium Development Goals. Lancet 2006;367(9514):955-957

96 Raviglione M, Zumla A, Marais B, Horton R, Motsoaledi A. A sustainable agenda for tuberculosis control and research. Lancet 2012;379(9821):1077-1078

97 World Health Organization. Global Tuberculosis Control: Surveillance, Planning, Financing. Geneva, Switzerland: WHO; 2007

98 Raviglione MC, Uplekar MW. WHO's new Stop TB Strategy. Lancet 2006:367(9514):952-955 